\title{
SAMBA, CACHAÇA E VIOLA: PATRIMÔNIO CULTURAL E MEMÓRIA LINGUÍSTICA EM FORMA DE CANÇÃO
}

Mestranda em Estudo de Linguagens pela Universidade do Estado da Bahia(UNEB) daisy_cordeiro@hotmail.com

Lúcia MariaParcero Doutora em Linguística pela Universidade Estadual de Campinas (UNICAMP) Professora da Universidade do Estado da Bahia(UNEB) Imparcero@gmail.com

\section{RESUMO}

Este artigo tem por objetivo analisar a canção Samba, cachaça e viola, de autoria do sambador João do Boi e gravada pelo grupo Samba Chula de São Braz, buscando refletir sobre como a poética oral do grupo trabalha com a memória para 0 fortalecimento da identidade e da valorização étnico-racial por meio do samba de roda, patrimônio histórico cultural imaterial da humanidade, e das influências das línguas africanas nos falares das sambadeiras e sambadores de roda na letra da cantiga. A metodologia empregada sustenta-se em uma abordagem qualitativa para a pesquisa, através de descrição linguística dos dados, revisão da literatura pertinente para tratar do tema da pesquisa e análise dos recursos linguísticos. De acordo com os resultados obtidos, as influências das línguas africanas estão presentes no léxico e em aspectos morfosintáticos, comprovando a manutenção da memória linguística e a afirmação da identidade étnico-racial dos falantes do Recôncavo baiano.

Palavras-chave: samba chula, línguas africanas, oralidade, patrimônio cultural, memória linguística.

\section{ABSTRACT}

This article aims to analyze the song Samba, cachaça e viola - written by Sambador João do Boi and recorded by the group Samba Chula de São Braz - and to reflect on how the oral poetry of the group may use memory in order to strengthening the Black identity and ethnic-racial valorization through the Samba de Roda, which is an Intangible Cultural Heritage of Humanity. Moreover, the article aims to analyze the influence of the African languages in the words of the sambadeiras and sambadores de roda in the lyrics of the song. The methodology used is based on a qualitative approach to the research, through linguistic description of the data, review of relevant literature to address the research topic, and analysis of linguistic resources. The results shows that African languages are an influence in the lexicon and morphosyntactic aspects of this community, proving the speaker of Recôncavos's permanent linguistic memory and affirmation of the ethnic- racialidentity.

Keywords: samba chula, African languages, orality, cultural patrimony, linguistic memory. 


\section{Introdução}

Este artigo tem por objetivo analisar a canção Samba, cachaça e viola, de autoria do sambador João Saturno, o João do Boi, e gravada pelo grupo Samba Chula de São Braz, buscando identificar influências das línguas africanas nos falares das sambadeiras e sambadores de roda na letra da cantiga. Calcado nos pressupostos teórico-metodológicos da Sociolinguística, o presente trabalho visa a contribuir para os estudos relacionados à memória linguística e às línguas africanas, que influenciaram a língua portuguesa do Brasil.

Os negros africanos traficados para o Brasil em condição de escravos, ao longo de três séculos, trouxeram não só a força de trabalho para os cultivos de cana-de-açúcar e café e para a extração de minérios para os senhores escravocratas; mas também muito de sua cultura, tecnologia, culinária, religiosidade, de seus costumes e de suas línguas, principalmente as dos grupos banto e kwa. Diversos são os ritmos musicais afro- brasileiros, mas para este trabalho destacaremos o samba de roda:

O samba de roda é uma manifestação musical, coreográfica, poética e festiva, presente em todo o estado da Bahia, mas muito particularmente na região do Recôncavo. Em sua definição mínima constitui-se da reunião, que pode ser fixada no calendário ou não, de grupo de pessoas para performance de um repertório musical e coreográfico [...] (IPHAN, 2006, p. 23).

Como elementos básicos para realização do evento samba de roda, há o posicionamento dos participantes em círculo (a roda) e o acompanhamento do canto por instrumentos como pandeiro, viola, prato-e-faca, entre outros. 
No ano de 2004 o samba de roda foi reconhecido como patrimônio cultural brasileiro pelo Instituto do Patrimônio Histórico e Artístico Nacional (IPHAN) e, em 2005, como patrimônio histórico cultural imaterial da humanidade pela Organização das Nações Unidas para a Educação, a Ciência e a Cultura (Unesco). O samba de roda faz parte da vida cultural de diversas cidades da Bahia. Somente no Território de Identidade Recôncavo há 120 grupos de samba de roda cadastrados na Associação dos Sambadores e Sambadeiras do Estado da Bahia (ASSEBA). A sede da ASSEBA é em Santo Amaro, na Casa do Samba, centro de referência para propagação da manifestação cultural e promoção de treinamentos, oficinas e pesquisa.

O contato da língua portuguesa com as línguas africanas durante a escravidão no Brasil propiciou muitas influências no português brasileiro. No Território de Identidade Recôncavo, região na qual está localizada a vila São Braz, havia dezenas de plantações dos grandes senhores escravocratas da Bahia. É provável que o processo de aquisição da língua portuguesa pelos africanos, nessa região, tenha se dado de forma simplificada; devido ao número de africanos ser maior que o de portugueses e também por causa das atividades laborais exercidas no campo, que envolviam muito mais trabalhos braçais que interações verbais. Diferentemente, os escravos urbanos na capital baiana, alguns deles chamados de escravos de ganhoi, vendiam produtos ou serviços e precisavam se comunicar na língua dos clientes, em português.

A tradição oral tem a voz como meio primordial de propagação e está fortemente ligada à memória individual e coletiva. Em relação ao seu conteúdo memorialístico, podese afirmar que este se constrói como tentativa de recuperação do passado. Para Izquierdo (2011, p. 11), a “[...] 'memória' significa aquisição, formação, conservação e evocação de informações". Em outras palavras, cabe ao texto memorialista registrar vivências, lembranças individuais e coletivas, sujeitas, inclusive, a distorções da memória, com vistas 
à retomada de um tempo, uma história, situada no contexto cultural, histórico e geográfico. Segundo Coutinho (2013, p. 12) “[...] a memória oral afrodescendente faz-se por meio do corpo em performance, de onde emanam poesia, música e dança, em diálogos continuamente (re) elaborados entre tradição e ruptura". Dessa forma, o presente trabalho busca demonstrar como a memória linguística de um povo pode estar registrada em uma cantiga de samba chula.

O estudo deste tema é pertinente para identificar como a preferência por palavras e expressões do vocabulário afro-brasileiro, na canção analisada, caracteriza a afirmação da identidade étnico-racial de falantes do Recôncavo; ou seja, o uso da língua para marcar seu lugar de resistência na sociedade. Além disso, esse tema torna-se relevante, pois visa a contribuir para os estudos linguísticos relacionados às línguas africanas, que influenciaram a língua portuguesa do Brasil.

\section{Entrando na roda: percorrendo os caminhos do patrimôniocultural}

O samba de roda tem como modalidades o samba chula e o samba corrido; sendo o corrido, muitas vezes, chamado simplesmente de samba de roda. O que diferencia uma modalidade da outra é que no samba chula a dança e o canto nunca acontecem ao mesmo tempo; enquanto, no samba corrido, ocorrem simultaneamente. No samba chula apenas uma pessoa de cada vez samba no meio da roda; enquanto, no samba corrido, várias pessoas dançam ao mesmo tempo no meio da roda, além de o ritmo ser mais acelerado.

Sobre o canto, ele pode ser responsorial: um dos sambadores canta sozinho uma 
estrofe e os demais participantes respondem coletivamente com outra estrofe. Essa forma de canto também está presente em outras manifestações de origem africana, como nas cerimônias de candomblé; sendo um membro religioso responsável por cantar sozinho, enquanto o público responde em conjunto. Essa modalidade ocorre apenas no samba corrido, também conhecido como samba solto. No samba chula, chamado também de samba de viola, samba amarrado, samba chulado ou samba santo-amarense, somente dois sambadores cantam, a parelha, podendo ter outra dupla que responde com poucos versos, o relativo.

O gênero musical samba de roda é caracterizado pela tradição oral, por ter suas canções memorizadas e transmitidas pelos mestres sambadores para os aprendizes, além de permitir improvisos. Há ainda grupos de samba que, até os dias atuais, não possuem registros das letras das músicas ou gravações. Além disso:

$\mathrm{Na}$ cultura da tradição oral, as "vozes ancestrais" reprimidas, porém resistentes, estão por toda parte, ainda mais no Recôncavo baiano, onde se respira a carga histórica de séculos de escravatura e das sequelas do período pós-abolição, aliado às sociabilidades político-econômicas que perpetuam um sistema colonialista baseado no poder de poucas famílias de ascendência portuguesa, no nepotismo, na troca de favores ou até mesmo na repressão direta, porém camuflada. As vozes ancestrais africanas ainda permeiam o Recôncavo em muitas dimensões, mas se transformaram ao longo dos anos em vozes de afirmação sociocultural e política, literalmente trazendo o passado presente, mediante a atuação da memória poético-musical. Outro dia ainda perseguidos, desprezados, infantilizados e rejeitados, as vozes, danças, gestualidades, e também os ritmos do tronco africano, se transformaram em patrimônio cultural que se faz presente no eixo central que a oralidade preenche nas comunidades negras rurais. A arte linguística da tradição oral se expressa pelo uso criativo da metáfora, do "sotaque", do subentendido, por vezes malicioso, brincalhão, sensual ou mesmo alertando, dando "recado", assim construindo uma prática discursiva que se alimenta da improvisação poético-musical e dos recursos performáticos e gestuais, compondo um acervo imensurável da memória e presença cultural dos 
filhos e das filhas da diáspora africana, perpetuado e transformado ao longo dos séculos da escravidão, repressão e pós-abolição (DÖRING, 2016, p. 10-11).

Os mestres e mestras do samba de roda estão partindo e com eles parte da essência do patrimônio imaterial. Poucos seguem o legado dos seus ancestrais, como o vocalista do Samba Chula de São Braz, Agnaldo de Oliveira Nascimento, que conta com muito orgulho:

[...] meus avós eram sambadores, meus pais eram sambadores e eu herdei, nasci e me criei ouvindo samba na minha casa. [...] e... isso aqui é... é a minha vida, eu tenho o maior prazer de participar desse Samba Chula de São Braz, porque relembra muito meus pais, meus avós. Eu canto hoje muita coisa aqui que a minha mãe que me ensinou, eu... a cada momento que eu canto uma chula aqui, não tem como esquecer. Porque foram as músicas que ela me... me ensinou, sabe?

Como pode ser observado, o samba de roda transcende a questão musical, está ligado à memória de um povo, à sua história de vida. Preservar o samba de roda exige um incentivo de política de salvaguarda do patrimônio cultural, mas também que se desperte o sentimento de pertencimento nos mais jovens, herdeiros das grandes sambadeiras e sambadores do Recôncavo.

\subsection{Recôncavo, Santo Amaro e São Braz: percurso sócio-histórico}

O Território de Identidade Recôncavo é formado pelos municípios Cabaceiras do Paraguaçu, Cachoeira, Castro Alves, Conceição do Almeida, Cruz das Almas, Dom Macedo Costa, Governador Mangabeira, Maragogipe, Muniz Ferreira, Muritiba, Nazaré, Salinas da 
Margarida, Santo Amaro, Santo Antônio de Jesus, São Felipe, São Félix, Sapeaçu, Saubara e Varzedo. A área total dos municípios que integram o território alcança 5,2 mil quilômetros quadrados com população aproximada de 576,7 mil habitantes, de acordo com a Superintendência de Estudos Econômicos e Sociais da Bahia (2016). Tem como características uma marcante riqueza cultural proporcionada pelos anos de exploração de mão-de-obra escrava e foi cenário de lutas pela independência da Bahia.

Segundo dados do Departamento Intersindical de Estatística e Estudos Socioeconômicos (DIEESE), o Recôncavo é o território com o maior porcentual de pessoas que se declaram pretas na Bahia - totalizando $28,2 \%$, além de $56,8 \%$ que se consideram pardas (no estado da Bahia o porcentual é de 17,0\% para pretos e 59,5\% para pardos). Temos, assim, uma região com população majoritariamente negra. A respeito do período de grande produção e exportação de açúcar, sabemos que: "No alvorecer dos setecentos, o Recôncavo baiano era uma das regiões mais produtivas da colônia portuguesa. O açúcar proporcionava um doce estado de riqueza e opulência aos senhores de engenho, que contrastava com a vida penosa e amarga dos cativos". (SOUZA, 2009, p. 54). Possivelmente, muitos dessa população negra, que vivem hoje no Recôncavo, descendem dos negros escravizados que trabalharam nos engenhos instalados na região no períodocolonial.

Apesar da riqueza adquirida pelos senhores de engenho e grandes comerciantes da época, uma grande massa de gente pobre formava a população do Recôncavo, e essa desigualdade é perceptível ainda hoje. Em pesquisa realizada em 2010, o Recôncavo apresentou porcentual de pessoas extremamente pobres de 15,1\% (BAHIA, 2016). Como comparação, no território Metropolitano de Salvador, o porcentual é de 6,1\%. Contrastando com palacetes - herança do período de abundância - e com construções mais recentes de prédios, há casebres, casas de taipa, barracões de lona. Ainda com dados de 2010, a taxa de analfabetismo foi de $15,8 \%$. 
O município de Santo Amaro está a 72 quilômetros de Salvador e é dividido em três distritos: a sede, Acupe e Oliveira dos Campinhos. Santo Amaro é conhecida por ter muitas manifestações culturais; entre elas, a festa de Nossa Senhora da Purificação, com procissão, missa especial e lavagem das escadarias da igreja da padroeira, e, claro, muito samba de roda.

São Braz fica a cerca de 7 quilômetros da sede de Santo Amaro e é uma das comunidades quilombolas do Recôncavo. Após receber a certificação, em 2009, pela Fundação Cultural Palmares, o povoado passa a ter direito a incentivos como apoio financeiro para a educação e manifestações culturais pelo Governo Federal, como política de reparação.

Pouco se tem de informações oficiais acerca da história da vila São Braz. Segundo pesquisa realizada por Santos (2014) - em sua dissertação de mestrado intitulada Ancestralidade e história no Recôncavo Baiano: construção do conhecimento ancestral no povoado de São Braz - em Santo Amaro, São Braz, foi, inicialmente, um engenho, construído entre os séculos XVII e XVIII. Após passar por vários proprietários e sucumbir ao declínio do mercado açucareiro na Bahia, foi abandonado e tornou-se quilombo, servindo de moradia para os antigos escravos do engenho e seus descendentes. Há ainda na localidade ruínas de uma capela dedicada ao santo católico São Braz, onde, conforme registros, houve missas e batismos entre os séculos XIX e XX. Muito do que se sabe sobre o passado da "afro-comunidade" é o que é contado pelos mais velhos aos mais novos. Desse modo, a tradição oral está fortemente presente na cultura das sambadeiras e dos sambadores do Samba Chula de São Braz. 


\title{
2. Samba, cachaça e viola: identidade e memória linguística
}

A canção a ser analisada faz parte do repertório de cantigas do grupo Samba Chula de São Braz, composta pelo mestre de chula João do Boi. A música foi gravada em 2009 no CD Quando eu dou minha risada, ha, ha..., porém o ano em que a canção foi escrita é desconhecido. O grupo foi fundado oficialmente em 1995 pelos irmãos Antônio Saturno, Seu Alumínio, e João do Boi, mas os dois irmãos já cantavam o samba chula há muitos anos no pequeno distrito de Santo Amaro. Seu João do Boi foi pescador e vaqueiro, vindo daí seu apelido. Em 2015, após a morte do irmão, João do Boi sai do grupo e forma o Samba Chula João do Boi.

O Samba Chula de São Braz é um dos principais grupos de samba do Recôncavo. O grupo se reúne quinzenalmente, aos domingos, para ensaiar. O local é o Restaurante de Fernando de Santana, que fica lotado de apreciadores do samba chula e da deliciosa culinária santo-amarense.

Abaixo, a transcrição da canção que será analisada com as marcas de oralidade da pronúncia dos intérpretes durante o canto:

\author{
SAMBA, CACHAÇA E VIOLA \\ Meu balaio, meu balaio, meu balaio \\ meu balaio, meu balaio, meu balaio \\ tira o maxixe da rama, bota o quiabo no pé \\ tira o maxixe da gaia, eu vou \\ eu vou com meu barco andá no mar \\ o vento bateu na vela \\ Balaio meu, balaio de opinião
}




$$
\begin{gathered}
\text { moça que não tem balaio } \\
\text { senta as cadeira no chão! } \\
\text { O rebolado que ela faz, o rebolado que ela faz } \\
\text { eu vou atrás pra ver, eu não posso mais } \\
\text { eu vou deixá minha marcação } \\
\text { atrás dessa garota anda muito gavião! } \\
\text { eu vou jogar, vou beber até cair } \\
\text { me dá, me dá, me dá, me dá um dinheiro aí } \\
\text { Quando eu dou minha risada, ha ha } \\
\text { quando eu dou minha risada, ha ha }
\end{gathered}
$$

[Nossa Senhora! Isso aí! Deixa comigo! Ô meu pandeiro, Kau! Esse é o Samba Chula de São Braz! Toca viola, menino]

$$
\begin{gathered}
\text { Ô violêro, toca violasereno } \\
\text { ô violêro, toca viola sereno } \\
\text { quem sabe lê não trabaia } \\
\text { só véve com a mão napena } \\
\text { ô violeiro, violeiro, toca viola serena, ha } \\
\text { Prender a lê, vô prender a lê } \\
\text { prender a lê pra dar lição a meus camará, ê he, meus camará } \\
\text { Por que bebe tanto assim, rapaz? } \\
\text { Você já bebeu demais! } \\
\text { você vai morrê sabeno } \\
\text { que a cachaça saborosa tem veneno } \\
\text { Eu lhe falei você não quis acreditá } \\
\text { que a cachaça tá “botano páquebrá” }
\end{gathered}
$$

(SAMBA CHULA DE SÃO BRAZ - Quando dou minha risada ha, ha ... - faixa 1. In: SAMBA CHULA DE SÃO BRAZ. Quando eu dou minha risada, ha ha... Coordenação e direção artística: Katharina Döring. Direção musical: Cássio Nobre. Plataforma de Lançamento, 2009.1 CD) 
Nessa cantiga, encontramos um dos temas mais recorrentes no samba chula: a mulher. Na primeira estrofe, os atributos físicos e a performance feminina durante a dança são destacados. Segundo Nina Graeff (2015, p. 47), “[...] balaio refere-se ao traseiro da dançarina, ou ao seu talento de balançá-lo, pois se ela não tem balaio, fica sentada com as 'cadeiras', isto é, com os quadris no chão".

Sobre as escolhas lexicais da cantiga, há lexias características do trabalho na roça (balaio, maxixe, rama, quiabo, pé, gaia), da pescaria (barco, mar, vela) e de momentos de lazer no samba de roda (rebolado, beber, violeiro, viola, cachaça). Sobre a cachaça, "é indispensável nas rodas de samba e serve como um verdadeiro combustível para os sambadores" (MASCARENHAS, 2014, p. 95). Ainda de acordo com a pesquisa de Mascarenhas (2014, p. 97):

Essa chula foi feita por Alumíno [sic] e seus companheiros para o amigo Saborosa. Nesta letra, a palavra saborosa possui sentido duplo para quem conhece a história de sua criação ou conhece Saborosa, professor de matemática de Santo Amaro [...] Este elemento lúdico enriquece a composição onde o nome do amigo, que está sendo alertado para os perigos do excesso da bebida, serve como elogio damesma.

É possível notar na canção a valorização da educação formal como meio de aquisição de poder e a visão negativa do trabalho braçal, que pode ser realizado por quem não sabe ler. Desse modo, ao aprender a ler, será possível "dar uma lição", ou seja, dominar, vencer, estar acima dos "camaradas".

Por outro lado, a relação negativa que o sujeito da enunciação apresenta com o trabalho braçal pode estar relacionado à memória do trabalho escravo, visto que a vila São Braz é um quilombo. Almejar adquirir maior conhecimento formal pode significar desejar se afastar dos trabalhos forçados, dos castigos, da dor, e a maneira de escapar dessa herança seria por meio da educação. 
Algumas lexias são de origem africana e estão no levantamento realizado pela etnolinguista Pessoa de Castro (2001), no livro Falares africanos na Bahia: um vocabulário afro-brasileiro, conforme lista abaixo:

CACHAÇA (banto) 1. (oiiBRiii) - s.f. aguardente que se obtém mediante a fermentação e destilação do mel ou borras do melaço; qualquer bebida alcoólica. Kikiv. kisasav ${ }^{v}$ lit. vi água ardente, que fermenta, excitante. 2. (BBR) - s.f. paixão, amor ardente, inclinação por alguém ou por alguma coisa. Kik. kisasa, qualquer coisa excitante, estimulante.

CAMARÁ (banto) (BR) - s.m. camarada, termo muito empregado em cânticos folclóricos.

MAXIXE (banto) 1. (ㅇBR) - s.m. fruto do maxixe(i)ro. Kik./Kimb vii. mansise/masisi.

QUIABO (banto) 1. (OBR) - s.m. fruto do quiabe(i)ro (Hibiscus esculentus L.), muito usado na cozinha cerimonial afro-brasileira e baiana.

SAMBA (banto) 1. (PS viii) - s.f. título de mameto. 2. (PS) - s.m. cerimônia pública de macumba. Kik/Kimb. (kuix) samba, rezar, orar. 3. (ВBR) - s.m. dança e música popular brasileira de compasso binário e acompanhamento sincopado; a música que acompanha essa dança. 4. (oBR) - s.m. (p.ext. ${ }^{x}$ ) festividade barulhenta acompanhada de dança; qualquer cerimônia pública, religiosa, afro-brasileira; confusão, barulho, briga.

Na pesquisa de Marroquim (1996), publicado em 1934, um dos primeiros a apresentar uma descrição sobre a fala na região Nordeste, também encontramos as lexias cachaça, maxixe, quiabo e samba como contribuições das línguas africanas para a variante nordestina do país. De acordo com Petter (2005, p. 211), “A presença africana no léxico é a mais forte evidência do contato linguístico e cultural". Sobre a lexia samba, para esta pesquisa, consideramos com o significado de dança e música popular brasileira e de festividade. E de fato, em seu uso sociocultural, o termo samba é utilizado indistintamente para a dança, o gênero musical e o evento (GRAEFF, 2015). A respeito dos aspectos linguísticos, há variedades estigmatizadas do português. As variantes estigmatizadas são as utilizadas pelas camadas mais baixas da sociedade, portanto, as camadas não prestigiadas. Quanto menos escolarizados, maior o uso das variantes estigmatizadas. 
Segue análise das variantes linguísticas encontradas na transcrição da canção Samba, cachaça e viola:

1. Vocalização da lateral palatal em gaia (pronúncia de ['gaye] no lugar do

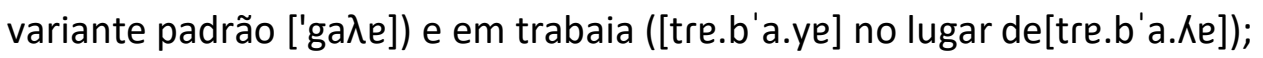

2. Não concordância nominal de número em as cadeira e meus camará;

3. Não aplicação das regras de flexão do verbo viver (uso de véve onde seria vive);

4. Redução do gerúndio em sabeno e botano;

5. A monotongação [ey] em violêro ([vio.l'e.ro] no lugar de[vio.l'ey.ro]);

6. Não realização do [r] final de palavras como andá, deixá, lê, morrê, acreditá, quebrá por apócope;

7. Ocorrência de aférese em 'prender;

8. Em pá ocorreu síncope;

9. Uso de the como pronome complemento de segunda pessoa.

Concordância nominal é um fenômeno de harmonia de gênero e número entre diversos nominais dentro do sintagma nominal, SN. Na concordância nominal, o núcleo determina o número e o gênero dos modificadores, determinantes, quantificadores e outros elementos não nucleares.

Estudos de linguistas brasileiros demonstraram que a não-concordância de número não se dá de modo aleatório, é possível sistematizar suas ocorrências e analisar os fatores condicionantes. Um desses fatores estruturais, que condicionam a concordância, trata do princípio da saliência fônica, segundo o qual "a falta de concordância ocorre mais frequentemente naqueles casos em que a diferença entre o singular e o plural é menor, ou menos saliente". (LEMLE; NARO, 1977, p. 42). "As cadeira" foi classificado como variante não estigmatizada levando em consideração o conceito de saliência fônica. 
A tendência em marcar o plural apenas nos artigos pode ser explicada pela influência do quimbundo, língua africana da família banta, que diferentemente das línguas indo-europeias não usa terminações para marcar o plural, mas sim prefixos. Dessa forma:

É possível, então, postular que os falantes de quimbundo, tendo de aprender português, identificaram nos artigos e outros determinantes dos nomes elementos semelhantes aos seus prefixos, de modo que não faziam a concordância dos nomes por flexões. Disso teriam resultado concordâncias como as casa, os menino, meus amigo, minhas terra, essas coisa, tão características das variedades rurais e urbanas brasileiras e também das variedades urbanas de prestígio, quando seus falantes se acham em situações de menor monitoramento, maior informalidade (BAGNO, 2011, p. 241).

Os usos de "gaia" e "trabaia" sofrem estigmatização, pois "[...] são mais limitados às zonas rurais e aos falantes de baixo status social." (PARCERO, 2007, p. 112). O fenômeno da vocalização ocorre por deslateralização, na qual o fonema $[\lambda]$ reduz-se à semivogal [y]. A não realização de $[\lambda]$ é um dos fenômenos registrados por Marroquim (1996) como característicos do falar nordestino.

Em "sabeno" e "botano" ocorreu redução ou assimilação do morfema identificador de gerúndio /ndo/ por [no]. Nesse processo fonológico, a consoante nasal /n/ nasaliza a vogal precedente e ocupa a posição de consoante inicial da sílaba final. Esse fenômeno ocorre na fala de pessoas cultas, não sendo considerado como uma variante estigmatizada. Já no caso de "véve", houve metafonia por abaixamento da vogal e sua realização sofre estigmatização.

Houve três casos de supressão de sons: em "pá" no lugar de "para" por síncope (supressão do fonema no interio do vocábulo); em "prendeu" no lugar de "aprendeu" por aférese (supressão de um som ou mais fonemas no início do vocábulo); e em "andá", "deixá", "lê", "morrê", "acreditá", "quebrá" por apócope (supressão do fonema no final). 
Este último caso pode ser explicado pelo fato de que, em iorubá e nas línguas do grupo banto, as palavras nunca terminam em consoante. Além disso, como afirma BortoniRicardo: "Em todas as regiões do Brasil, o /r/ pós-vocálico, independentemente da forma como é pronunciado, tende a ser suprimido, especialmente nos infinitivos verbais (correr > corrê; almoçar > almoçá; desenvolver > desenvolvê; sorrir > sorri)." (BORTONI-RICARDO, 2004, p. 85). Entretanto, segundo Marroquim (1996) esse fenômeno deve-se à lei do menor esforço, visto que, entre as línguas românicas, a eliminação do r final ocorre também no romeno, sem a influência de línguas africanas. Por não ser um fenômeno exclusivo das classes mais baixas e menos escolarizadas, não é uma variação estigmatizada.

Em "violero" o ditongo [ey] se transformou na vogal [e] antes de [r] por assimilação do [y], palatal, com a consoante. Segundo Marroquim (1996, p. 51), trata-se de "[...] um fenômeno comum entre o povo e entre as pessoas cultas." O autor acredita que essa pronúncia tenha sido regular no português e traz como exemplo a ocorrência da grafia de peixes como pêxes em Os Lusíadas.

A maioria dos integrantes do grupo e participantes desta pesquisa, nasceu e mora em São Braz. É possível deduzir que seus falares têm marcas dos falares dos seus pais, avós, etc. Conforme Santos:

Após o entendimento sobre a sucessão de proprietários do engenho e depois povoado, e as constatações presentes na lista dos moradores do século XVIII, podemos concluir que existindo São Braz desde o século XVII, registrando um número de cem moradores no XVIII e aproximadamente 1085 no XXI, como aponta o recenseamento do IBGE, associado à característica de pouco êxodo entre os moradores, não seria incorreto inferir que houve pouco aumento populacional, considerando pouco mais de três séculos de existência da localidade. Notória também é a grande mobilidade que ocorre na região, isso por ela estar inserida em um contexto de modernização da sociedade, não sendo contemplativas, do ponto de vista financeiro, as atividades manuais que ainda são desenvolvidas no local. Dessa forma, se pouco é o crescimento populacional associado ao êxodo, grande tende a ser a manutenção das 
tradições culturais muito provavelmente originárias de sua formação (SANTOS, 2014, p. 34-35).

Assim como muito das tradições culturais foram mantidas, a memória linguística dos seus antepassados pode ter se mantido.

\section{Considerações finais}

Pelo exposto até aqui, é possível verificar a influência das línguas africanas na canção Samba, cachaça e viola do grupo santoamarense Samba Chula de São Braz. Tais influências podem ser comprovadas tanto no léxico, com a presença de palavras de origem banto; quanto em aspectos morfossintáticos, como no caso da marca de plural apenas nos determinantes e o uso dos pronomes dativos e acusativos com as mesmas formas. Segundo afirma Bagno, “o elemento africano sem dúvida é responsável por muitas das características gramaticais específicas do PB, características que tornam o PB diferente não só do português europeu como também das demais línguas da família românica" (BAGNO, 2011, p. 236). Dessa forma, a memória linguística dos afrodescendentes da comunidade de São Braz está registrada em uma das suas cantigas de samba de roda: Patrimônio Histórico Cultural Imaterial da Humanidade e motivo de orgulho e alegrias do povo negro do Recôncavo.

\section{Referências}

BAGNO, M. Gramática pedagógica do português brasileiro. São Paulo: Parábola Editorial, 2011.

BAHIA. Superintendência de Estudos Econômicos e Sociais da Bahia. Perfil dos Territórios de Identidade. Salvador: SEI, v. 2, 2016. Disponível

em: < http://www.sei.ba.gov.br/index.$p h p$ ?option=com_content\&view=article\&id=2289\& 
Itemid=265>. Acesso em: 26 mar. 2018.

BOI, J. Samba, cachaça e viola. In: Samba Chula de São Braz. Quando eu dou minha risada ha ha... Plataforma de Lançamento, 2009.1 CD. Faixa 1.

BORTONI-RICARDO, S. M. Educação em língua materna: a sociolinguística na sala de aula. São Paulo: Parábola, 2004.

COUTINHO, I. V. B. F. Dos volteios do verbo à grafia do corpo: o samba de roda no universo das letras. Nau Literária. Porto Alegre: UFRGS, v. 9, n. 1, jan./jul. 2013.

Disponível em:<http://www.seer.ufrgs.br/NauLiteraria/article/viewFile/43396/27890>. Acesso em: 10 nov. 2018.

DIEESE. Educação Profissional da Bahia e Territórios de Identidade. Salvador: DIEESE, 2014. v. 2. Disponível em:

<https://www.dieese.org.br/anuario/2014/anuarioEducacaoProfissioanalBahiaTerritorios Identidade.pdf >. Acesso em: 26 out. 2018.

DÖRING, K. Contador de chula: o samba antigo do Recôncavo. Salvador: Pinaúna, 2016.

GRAEFF, N. Os ritmos da roda: tradição e transformação no samba de roda. Salvador: EDUFBA, 2015.

IPHAN. Samba de Roda do Recôncavo Baiano. Dossiê IPHAN 4: Ministério da Cultura, 2006.

IZQUIERDO, I. Memória. 2. ed. Porto Alegre: Artmed, 2011.

LEMLE, M.; NARO, A. J. Competências básicas do português. Relatório final de pesquisa apresentado às instituições patrocinadoras Fundação Movimento Brasileiro (MOBRAL) e Fundação Ford: Rio de Janeiro, 1977.

MARROQUIM, M. A língua do Nordeste: Alagoas e Pernambuco. 3. ed. Curitiba: HD Livros, 1996.

MASCARENHAS, J. G. P. A representação do cotidiano no samba chula do recôncavo baiano: as letras da chula e o grupo de samba chula de São Braz. 2014. 136 f. Dissertação (Mestrado em Ciências Sociais) - Universidade Federal da Bahia, Salvador, 2014.

PARCERO, L. M. J. Fazenda Maracujá: sua gente, sua língua, suas crenças. 2007. 191 f. Tese (Doutorado em Linguística) - Universidade Estadual de Campinas. Campinas, 2007.

PESSOA DE CASTRO, Y. Falares africanos na Bahia: um vocabulário afro-brasileiro. Rio de Janeiro: Academia Brasileira de Letras/ Topbooks Editora, 2001.

PETTER, M. M. T. Línguas africanas no Brasil. Gragoatá. Niterói: UFF, n. 19, p. 193-217, 2005. Disponível em: 
<http://www.gragoata.uff.br/index.php/gragoata/article/view/351/350>. Acesso em: 14 nov. 2018.

SANTOS, A. A. Ancestralidade e história no Recôncavo Baiano: construção do conhecimento ancestral no povoado de São Braz, em Santo Amaro. 2014. 130 f. Dissertação (Mestrado em Educação) - Universidade do Estado da Bahia, Salvador, 2014.

SOUZA, D. S. de. Na teia da escravidão: trabalho e resistência no Recôncavo baiano na primeira metade do século XVIII. Revista de História, v. 1, n. 1, p. 53-73, 2009. Disponível em: <http://www.revistahistoria.ufba.br/2009_1/a04.pdf>. Acesso em: 10 nov. 2018.

Recebido em 13 de julho de 2018.

Aceite em 7 de novembro de 2018.

\footnotetext{
(ALBUQUERQUE; FRAGA FILHO, 2006, p 84).

ii Dicionarizado no Aurélio.

iii Português do Brasil.

${ }^{\text {iv }}$ Quicongo e seu conjunto de dialetos (quitando, quitari, etc.).

${ }^{\vee}$ Étimo africano

${ }^{\mathrm{vi}}$ Literalmente.

vii Quimbundo e seu conjunto de dialetos.

viii Povo de santo, comunidade religiosa afro-brasileira.

${ }^{\text {ix }}$ Classe de prefixo que indica infinitivo verbal.

${ }^{\mathrm{x}}$ Por extensão de sentido.
}

i "Os escravos de ganho faziam alguns serviços nas casas dos senhores e iam para as ruas em busca de trabalho. Alugavam seu tempo a um e a outro, e ao final do dia ou da semana deviam entregar uma determinada soma ao seu senhor ou senhora. O que passava disso os escravos embolsavam". 